\title{
Infection-Related Cancers in Sub-Saharan Africa: A Paradigm for Cancer Prevention and Control
}

\author{
Fred Okuku ${ }^{a}$ Abrahams Omoding ${ }^{a}$ Victoria Walusansa ${ }^{a}$ Martin Origa $^{a}$ \\ Gerald Mutungi ${ }^{\mathrm{b}}$ Jackson Orem ${ }^{\mathrm{a}}$ \\ a Uganda Cancer Institute, and b Non-Communicable Diseases Desk, Ministry of Health, Kampala, Uganda
}

\section{Key Words}

Infection - Cancer - Sub-Saharan Africa - Communicable

diseases $\cdot$ Noncommunicable diseases

\begin{abstract}
There is much commonality between chronic noncommunicable and communicable diseases which is best exemplified by cancers of infectious origin. It provides the perfect opportunity for harnessing the advances that have been made in the control of communicable diseases to attempt the control of noncommunicable diseases. There are possibilities at various levels of intervention, at primary, secondary and tertiary levels, which fit well within a well-planned national cancer control strategy. Prevention should proceed through steps of disruption of transmission, improvement in disease recognition and diagnosis, as well as through prompt effective treatment. This principle should work for both infection and the resultant cancer. Research is very important in understanding how best to use the available knowledge and how best to sequentially implement strategies. Finally, policies that acknowledge infection-related cancers as a major problem in the region should be in place.
\end{abstract}

Copyright $\odot 2012$ S. Karger AG, Basel

\section{KARGER}

Fax +4161306 1234 E-Mail karger@karger.ch www.karger.com
(C) 2012 S. Karger AG, Basel

0030-2414/13/0842-0075\$38.00/0

Accessible online at:

www.karger.com/ocl

\section{Introduction}

The global cancer burden will increase by 6 million (in the years 2000-2020, according to the WHO) and most of this increase will be in the developing countries, especially in sub-Saharan Africa [1]. Thirty percent of cancers in these countries are related to infection, and most cancer patients are young and in their prime as opposed to the elderly cancer population in the developed world [2]. HIV has emerged as a major factor in the accelerated burden of cancer in the region $[3,4]$. Therefore, cancer is being increasingly recognized as an important global health problem killing more people worldwide than HIV, tuberculosis and malaria combined. Nearly two thirds of these deaths occur in the developing world. Proportionately, one third of cancer is preventable, one third treatable and curable and the other third is managed palliatively [5] (fig. 1).

In Africa, there is a general lack of understanding of the true burden and incidence of cancers [6-8]. The most recent cancer data from the WHO/IARC database provides information from a few countries: Egypt, Algeria, Tunisia, Uganda and Zimbabwe. Population-based cancer registries, the most reliable method for cancer surveillance, cover only $11 \%$ of the population on the continent [9-11]. However, the current available information shows

Dr. Jackson Orem

Uganda Cancer Institute

Upper Mulago Road, PO Box 3935

Kampala (Uganda)

E-Mail JOrem@mucwru.or.ug 


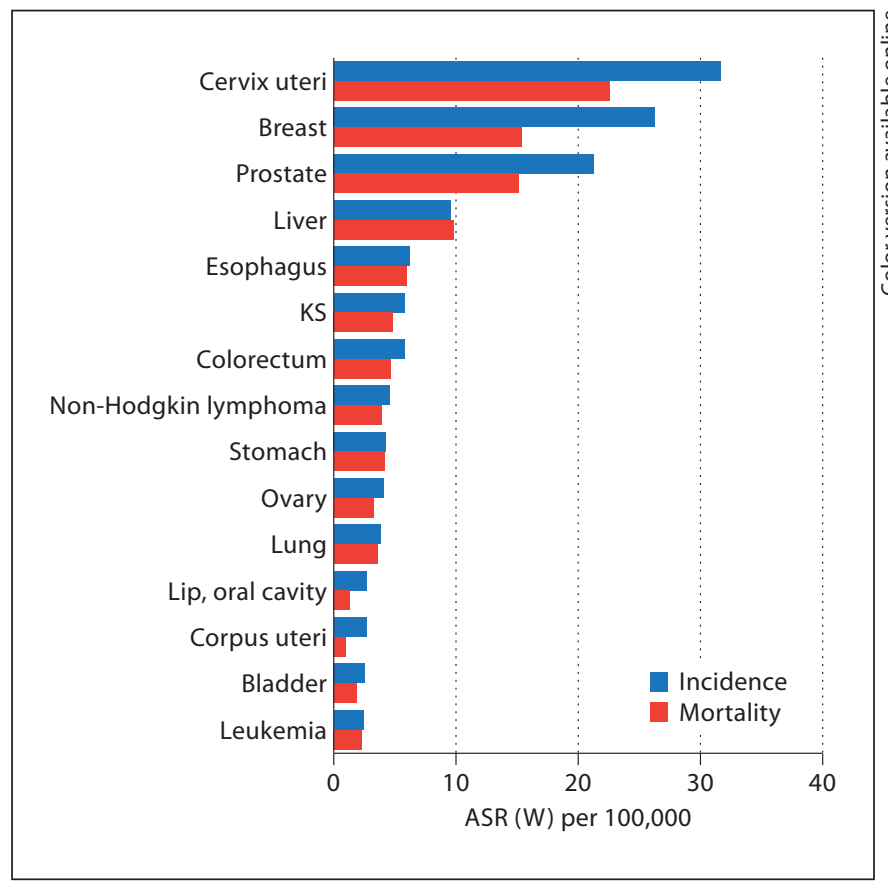

Fig. 1. Incidence and mortality of cancer in sub-Saharan Africa. ASR $(W)=$ Age-standardized mortality rate (world). Source: Globcan 2008.

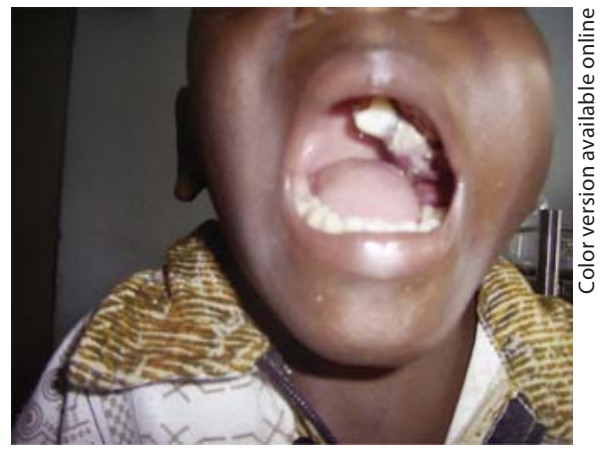

Fig. 2. A child with BL in Uganda.

that the commonest cancers in Africa are breast, cervix, liver, prostate and Kaposi sarcoma (KS). It is important to note that overall, 3 out of 5 of the commonest cancers in this setting are related to infection.

At country level, we are familiar with the situation in Uganda which best outlines the cancer burden in most sub-Saharan African countries. There are more than 60,000 cases of cancer per year, of which 25,000 are incident cases. Each year, about 22,000 deaths occur in Uganda due to cancer. In addition, the risk of cancer before the age of 65 years is $10 \%$, and in the next 5 years, it is estimated that there will be 80,000 new cancer cases in the country at any one time. At service level, there is a national center for treatment of cancers, the Uganda Cancer Institute, where 2,000 newly diagnosed cases of cancers are attended to per year. This is only $4 \%$ of the new cases in the whole country [12]. Currently, $60 \%$ of cancer cases are directly attributed to HIV infection, yet there is no access to support under current HIV programs, such as Global Fund and PEPFAR, for the concomintant care for these cancers. Therefore, the HIV-infected population is harboring a very high risk and burden of cancer in Africa, albeit without substantial support.

Childhood cancers are equally very common, with Burkitt lymphoma (BL), a fast-growing malignant tumor affecting the jaw or abdomen of children, being the commonest (fig. 2). The prognosis of $\mathrm{BL}$ is excellent following treatment using chemotherapy alone and there is a potential for cure even in advanced stages of the disease. It is unfortunate that this cancer still has a high mortality rate in Africa, mainly due to poor access to proper care [13].

\section{Infection and Cancer}

Cancers related to infection in Africa include KS, BL, liver cancer, cervical cancer and gastric malignancies. Kaposi sarcoma herpes virus (KSHV) also known as human herpes virus 8 (HHV-8), human papillomavirus (HPV), Hepatitis B virus, and Epstein-Barr virus (EBV) are common cancer-related viral infections in this population [2].

The incidence of cancer is high in HIV-infected individuals, and hence, HIV is an important infectious cofactor despite no clear direct etiologic role [14]. People infected with HIV are several thousand times more likely than uninfected persons to be diagnosed with KS [15]. HIV-positive women are at least 5 times more likely to be diagnosed with cervical cancer, which is caused by HPV $[16,17]$. HIV patients are 70 times more likely to be diagnosed with non-Hodgkin lymphoma [18]. Again, all these cancers in the HIV population are related to other infections. Therefore, despite the increasing use of antiretroviral therapy (ART), HIV-positive individuals will still be more vulnerable to cancers $[19,20]$.

We can say that a number of cancers in Africa have known infectious causes and fairly known mechanisms of cellular transformation process. This offers prospects for targeted interventions aimed at prevention and for control with current and emerging technologies. The en- 
tire mechanism for the development of various infectionrelated tumors may not be well known and is subject to further elucidation. However, in general, virus-associated malignancies develop more frequently in individuals whose immune system is compromised by infection with HIV-1 or by use of immunosuppressive drugs after receiving organ transplants [21]. EBV-associated B-cell lymphomas, KS herpes virus (KSHV)-associated KS and HPV-related cervical cancer are among the most common malignancies seen in this context. The individual host factors, such as the immune status, are very important indicators of who is at risk of cancer, and hence, we can stratify individuals according to risk groups. In general, ongoing viral replication plays a key role in the development or sustenance of cancer state [22]. For instance, the presence of replicating HHV-8 in the peripheral blood has been shown to be one of the strongest predictors of the development of KS, and in vitro work has revealed that a small proportion of HHV-8 infection in the lytic phase is required for the initiation and progression of KS tumors [23]. These observations may explain the high incidence and imply that antiviral therapy aimed at interrupting KSHV replication may have a role in the prevention or treatment of cancer related to viral infection [24].

\section{Approaches to Infection-Related Cancers and Implication for Noncommunicable Disease Control}

The main challenge in translating the successes in the knowledge of cancer causes, as elucidated above, into public health programs is the lack of tangible indicators of success in developing countries. This is mainly due to the lack of capacity for early detection, patient evaluation and population-based cancer registries. This is further aggravated by a lack of awareness leading to late presentation and by cancer not being a notifiable disease in most countries. Despite these limitations, attempts at controlling infection-related cancers are needed. The most obvious target should naturally be preventing infection and controlling ongoing disease process such as replication in new and ongoing disease. A glimpse of how this can work could be gained by considering HIV, where a number of cancers can potentially be controlled by highly active ART (HAART). This strategy is possibly already paying dividend by preventing many potential cancer cases [25]. Using our understanding of the infectious disease process in cancer causation will further help in guiding interventions, with benefits going beyond individual cases to the population.

Infection-Related Cancers in

Sub-Saharan Africa

\section{Vaccine Approach}

The best example of a shared approach for the intervention of communicable diseases and cancer is coming from the use of vaccination [26]. Vaccines have emerged as the most successful approach ever for preventing communicable diseases, and the science of vaccines is one of the most promising areas of ongoing cancer prevention research. There is an opportunity for a shared approach, with the advantage of limited toxicity compared to other treatments. There are two approaches to vaccination: (1) aiming at the prevention of infection (prophylactic), and (2) aiming at the prevention of disease development following infection (therapeutic).

The vaccine against hepatitis $B$, the cause of chronic liver diseases such as liver cancer, is a prototype of this approach [26]. It has already been shown to be very successful and a leading example of a new direction for controlling cancers [27]. Since its introduction, there has been a marked reduction in chronic liver disease including hepatocellular carcinoma. This is very important since liver cancer is one of the leading causes of cancer deaths in men in sub-Saharan Africa. Hepatitis B virus vaccination is already serving as a model for the global control of another important viral cause of cancer, HPVrelated cervical cancer [28]. HPV vaccines are highly effective in preventing HPV infection and precancerous lesions in women, and the quadrivalent vaccine has an extended efficacy to a number of conditions such as genital warts in men and women and precancerous anal lesions in men in the developed world [29]. Other HPV-related cancers that can potentially benefit from HPV vaccine include oropharyngeal cancers and HPV-related penile cancers. Already, the focus is turning to these other cancers in industrial countries, where cervical screening is effective, causing reevaluation of male HPV immunization [30]. The effectiveness of vaccines in drastically reducing once highly prevalent and devastating infections close to elimination is very motivating for the development of vaccines for infection-related cancers. There is a need to accelerate the progress in the development of cancer vaccine to avoid virus carriers and susceptible individuals at high risk from dying of potentially preventable causes. There is optimism that vaccines based on live attenuated viruses for a number of other gamma herpes viruses that commonly cause cancer may soon be available [31].

\section{Antibacterial Approach}

A prototype of an antibacterial approach to cancer prevention is the treatment of Helicobacter pylori. Eradi- 


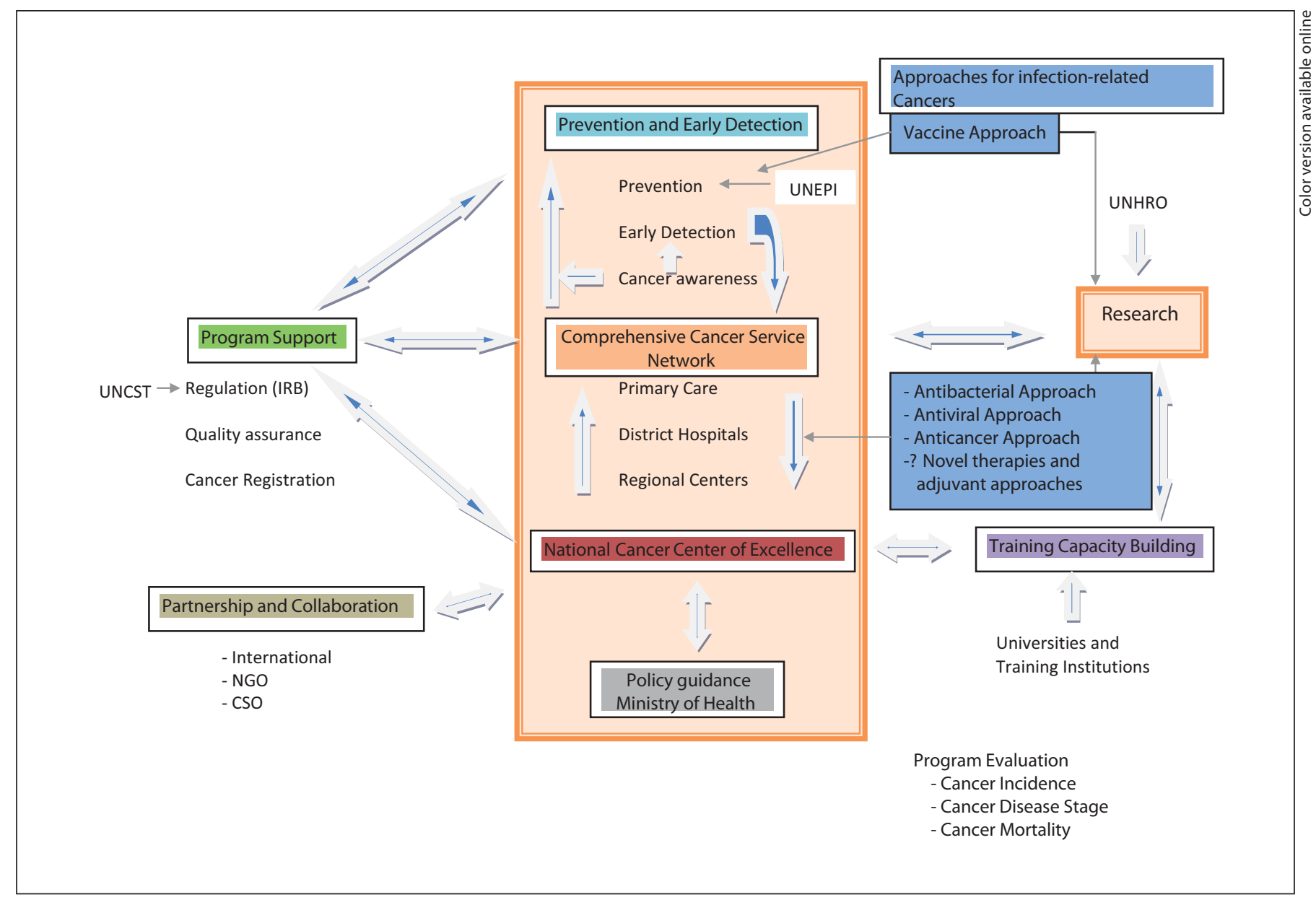

Fig. 3. Outline of the Uganda Comprehensive National Cancer Control Program. UNCST = Uganda National Council for Science and Technology; IRB = institutional review board; NGO = non-governmental organization; CSO = civil society; UNEPI = Uganda National Expanded Program for Immunization; UNHRO = Uganda National Health Research Organization. cation of $H$. pylori is needed for patients with $H$. pylori gastritis, and early $H$. pylori eradication is known to lead to a decreased risk of gastric cancer in patients with peptic ulcer diseases [32]. It is over two decades ago since the discovery of $H$. pylori as cause of gastric ulcer and cancer. Gastric cancer is common in Africa, and hence, an approach targeting the infectious cause would be ideal [33]. Moreover, effective treatment with antibiotics in combination with good hygiene would wipe out gastric cancers.

\section{Antiviral Approach}

Currently, several antiviral drugs are in use for the treatment of chronic hepatitis B virus infection worldwide $[34,35]$. However, there is limited access to treatment in many resource-constrained settings, where most patients are found [36]. Antiviral therapies have been shown to delay progression of cirrhosis and lower the incidence of hepatocellular carcinoma, with the advantage of improving long-term survival [36]. A good number of these drugs have been shown to be useful in the treatment of HIV; such drugs include tenofovir, lamivudine and emtricitabine, hence providing the opportunity for synergy with HIV programs [35]. A further lesson learnt from HIV treatment is the impact of HAART in reducing the incidence of various cancers in the HIV population. It is well known that part of the benefit is directly attributed to the control of viral replication by ART [36]. Moreover, HAART is a potent inhibitor of HHV-8 replication, and thus, combinations of antiviral therapy with HAART to prevent HHV-8-associated disease appear warranted in potentially controlling $\mathrm{HHV}$-8-associated diseases. 


\section{Anticancer Approach}

Most cancers resulting from infectious causes are fast growing, and thus, amendable to treatment with a good outcome. Therefore, chemotherapy is the most effective method for curing these cancers even in advanced stages of the disease. This is best exemplified by BL treatment response and outcome [37]. The aggressive nature of some forms of endemic disease implies that chemotherapy must be given promptly. The goals of treatment should be eradication or potential cure of disease using systemic combination chemotherapy.

\section{Novel Therapies and Adjuvant Approaches}

Many infection-related cancers exhibit ideal targets for molecularly directed therapy [38]. For instance, KSHV is known to have several protooncogenes with upregulation of platelet-derived growth factor receptor and c-kit and increased proliferation in the presence of ligand [39]. These are ideal for small molecules or targeted therapy [40]. Other therapies such as vascular endothelial growth factor inhibitors should be considered potentially useful. Lytic cycle activation of EBV using sodium valproate has been shown to enhance the response to chemotherapy and antiviral agents, with potential in adjunctive treatment of EBV-associated cancers such as BL and nasopharyngeal carcinomas [41].

\section{Prevention and Control of Infection-Related Cancers}

The high rate of infection-related cancers in sub-Saharan Africa makes prevention and control a priority. The populations with the greatest need must be identified through risk stratification so that interventions can be fitted within the scope of a national cancer control program.

In Uganda, hepatitis B has now been included in the routine national immunization schedule and is hence available to all children. In addition, there are hepatitis B immunization policies for all at risk or exposed due to occupation or workplace.

HPV vaccination is in the roll-out phase for pre-teen girls, and in the next 5 years, all districts in the country would be covered.
There are still challenges in fitting specific treatments for chronic hepatitis B within existing health facilities using antiviral agents. However, access to specific cancer therapies are expanding through specialized treatment facilities with the encouragement of unified protocols through treatment networks of the Uganda Cancer Institute. Most important of all is the creation of community awareness as part of a comprehensive cancer service (fig. 3 ).

\section{Conclusions}

There is much commonality between chronic noncommunicable and communicable diseases which is best exemplified by cancers of infectious origin. It provides a perfect opportunity for harnessing the advances that have been made in the control of communicable diseases to attempt the control of noncommunicable diseases. There are possibilities at various levels of intervention, at primary, secondary and tertiary levels, which fit well within a well-planned national cancer control strategy. Prevention should proceed through steps of disruption of transmission, improvement in disease recognition and diagnosis, and prompt effective treatment. This principle should work for both infection and the resultant cancer.

Research is very important in understanding how best to use the available knowledge and experience from infectious diseases via infection-related cancer for the control of cancers in general. Research will be the key to implementation of strategies. Finally, policies that acknowledge infection-related cancers as a major problem in the region should be in place.

\section{Acknowledgements}

We thank our colleagues and the staff of the Uganda Cancer Institute.

\section{Disclosure Statement}

The authors declare no conflicts of interest.
References

Infection-Related Cancers in

Sub-Saharan Africa
Thun MJ, DeLancey JO, Center MM, Jemal A, Ward EM: The global burden of cancer: priorities for prevention. Carcinogenesis 2010;31:100-110.

2 Parkin DM: The global health burden of infection-associated cancers in the year 2002. Int J Cancer 2006;118:3030-3044.

\footnotetext{
3 Franceschi S: HIV and cancer in Africa. Int J Cancer 2001;92:621.

-4 Stefan DC, Wessels G, Poole J, Wainwright L, Stones D, Johnston WT, et al: Infection with human immunodeficiency virus-1 (HIV) among children with cancer in South Africa. Pediatr Blood Cancer 2011;56:77-79.
} 
5 Wise J: A third of all cancers in the UK are potentially preventable, finds review. BMJ 2011;343:d7999.

6 Jemal A, Bray F, Forman D, O’Brien M, Ferlay J, Center M, et al: Cancer burden in Africa and opportunities for prevention. Cancer 2012;118:4372-4384.

7 Chokunonga E, Borok MZ, Chirenje ZM, Nyabakau AM, Parkin DM: Cancer survival in Harare, Zimbabwe, 1993-1997. IARC Sci Publ 2011:249-55.

8 Wabinga H, Parkin DM, Nambooze S, Amero J: Cancer survival in Kampala, Uganda, 1993-1997. IARC Sci Publ 2011:243-247.

$\checkmark 9$ Parkin DM, Wabinga H, Nambooze S: Completeness in an African cancer registry. Cancer Causes Control 2001;12:147-152.

10 Parkin DM: International variation. Oncogene 2004;23:6329-6340.

11 Einstein $\mathrm{MH}$, Phaeton R: Issues in cervical cancer incidence and treatment in HIV. Curr Opin Oncol 2010;22:449-455.

12 Orem J, Wabinga H: The roles of national cancer research institutions in evolving a comprehensive cancer control program in a developing country: experience from Uganda. Oncology 2009;77:272-280.

-13 Mbulaiteye SM, Talisuna AO, Ogwang MD, McKenzie FE, Ziegler JL, Parkin DM: African Burkitt's lymphoma: could collaboration with HIV-1 and malaria programmes reduce the high mortality rate? Lancet 2010;375: 1661-1663.

14 Mbulaiteye SM, Katabira ET, Wabinga H, Parkin DM, Virgo P, Ochai R, et al: Spectrum of cancers among HIV-infected persons in Africa: the Uganda AIDS-Cancer Registry Match Study. Int J Cancer 2006;118:985-990.

-15 Ziegler J, Newton R, Bourboulia D, Casabonne D, Beral V, Mbidde E, et al: Risk factors for Kaposi's sarcoma: a case-control study of HIV-seronegative people in Uganda. Int J Cancer 2003;103:233-240.

- 16 Gaym A, Mashego M, Kharsany AB, Walldorf J, Frohlich J, Karim QA: High prevalence of abnormal Pap smears among young women co-infected with HIV in rural South Africa - implications for cervical cancer screening policies in high HIV prevalence populations. S Afr Med J 2007;97:120-123.

17 Moodley M, Mould S: Invasive cervical cancer and human immunodeficiency virus (HIV) infection in KwaZulu-Natal, South Africa. J Obstet Gynaecol 2005;25:706-710.

- 18 Pluda J, Yarchoan R: For HIV patients survival increases the risk of lymphoma. RN 1990;53:144.
19 Bohlius J, Schmidlin K, Costagliola D, Fatkenheuer G, May M, Caro-Murillo AM, et al: Incidence and risk factors of HIV-related non-Hodgkin's lymphoma in the era of combination antiretroviral therapy: a European multicohort study. Antivir Ther 2009;14 1065-1074.

20 Piketty C, Selinger-Leneman H, Grabar S, Duvivier C, Bonmarchand M, Abramowitz $\mathrm{L}$, et al: Marked increase in the incidence of invasive anal cancer among HIV-infected patients despite treatment with combination antiretroviral therapy. AIDS 2008;22:12031211.

21 Cobucci RN, Saconato H, Lima PH, Rodrigues HM, Prudencio TL, Junior JE, et al: Comparative incidence of cancer in HIVAIDS patients and transplant recipients. Cancer Epidemiol 2012;36:e69-e73.

22 Silverberg MJ, Chao C, Leyden WA, Xu L, Horberg MA, Klein D, et al: HIV infection, immunodeficiency, viral replication, and the risk of cancer. Cancer Epidemiol Biomarkers Prev 2011;20:2551-2559.

23 Lukac DM, Yuan Y: Reactivation and lytic replication of KSHV; in Arvin A, Campadelli-Fiume G, Mocarski E, Moore PS, Roizman B, Whitley R, Yamanishi K (eds): Human Herpesviruses: Biology, Therapy and Immunoprophylaxis. Cambridge, Cambridge University Press, 2007.

24 Ziegler JL, Simonart T, Snoeck R: Kaposi's sarcoma, oncogenic viruses, and iron. J Clin Virol 2001;20:127-130.

25 Atashili J, Smith JS, Adimora AA, Eron J, Miller WC, Myers E: Potential impact of antiretroviral therapy and screening on cervical cancer mortality in HIV-positive women in sub-Saharan Africa: a simulation. PLoS One 2011;6:e18527.

26 Blumberg BS: Hepatitis B virus, the vaccine, and the control of primary cancer of the liver. Proc Natl Acad Sci USA 1997;94:7121-7125.

27 Nayak NC: Vaccine against hepatocellular carcinoma - prospects of a new era in cancer control. Indian J Med Res 1983;78(suppl): $1-7$.

28 The first vaccine for control of cervical cancer. J Pharm Belg 1999;54:59.

29 Basu M: The relevance of cervical cancer screening and the future of cervical cancer control in India in the light of the approval of the vaccine against cervical cancer. Indian J Cancer 2006;43:139.
30 Bryan JT: Developing an HPV vaccine to prevent cervical cancer and genital warts. Vaccine 2007;25:3001-3006.

31 Goodman L: EBV conference establishes goals for defining disease-related EBV subtypes for vaccine development. Ai Zheng 2009;28:1233-1235.

$32 \mathrm{Wu}$ CY, Kuo KN, Wu MS, Chen YJ, Wang $\mathrm{CB}$, Lin JT: Early Helicobacter pylori eradication decreases risk of gastric cancer in patients with peptic ulcer disease. Gastroenterology 2009;137:1641-1648.e1-2.

-33 Newton R, Ziegler JL, Casabonne D, Carpenter L, Gold BD, Owens M, et al: Helicobacter pylori and cancer among adults in Uganda. Infect Agent Cancer 2006;1:5

34 Liaw YF, Sung JJ, Chow WC, Farrell G, Lee $\mathrm{CZ}$, Yuen $\mathrm{H}$, et al: Lamivudine for patients with chronic hepatitis B and advanced liver disease. N Engl J Med 2004;351:1521-1531.

35 Lin PF, Nowicka-Sans B, Terry B, Zhang S, Wang C, Fan L, et al: Entecavir exhibits inhibitory activity against human immunodeficiency virus under conditions of reduced viral challenge. Antimicrob Agents Chemother 2008;52:1759-1767.

36 Wiersma ST, McMahon B, Pawlotsky JM, Thio CL, Thursz M, Lim SG, et al: Treatment of chronic hepatitis B virus infection in resource-constrained settings: expert panel consensus. Liver Int 2012;32:174.

- 37 Orem J, Mulumba Y, Algeri S, Bellocco R, Mangen FW, Mbidde EK, et al: Clinical characteristics, treatment and outcome of childhood Burkitt's lymphoma at the Uganda Cancer Institute. Trans R Soc Trop Med Hyg 2011;105:717-726.

38 Weidanz JA, Hildebrand WH: Expanding the targets available to therapeutic antibodies via novel disease-specific markers. Int Rev Immunol 2011;30:312-327.

-39 Dezube BJ, Sullivan R, Koon HB: Emerging targets and novel strategies in the treatment of AIDS-related Kaposi's sarcoma: bidirectional translational science. J Cell Physiol 2006;209:659-662.

-40 Pantanowitz L, Schwartz EJ, Dezube BJ, Kohler S, Dorfman RF, Tahan SR: C-Kit (CD117) expression in AIDS-related, classic, and African endemic Kaposi sarcoma. Appl Immunohistochem Mol Morphol 2005;13: 162-166.

41 Feng WH, Kenney SC: Valproic acid enhances the efficacy of chemotherapy in EBV-positive tumors by increasing lytic viral gene expression. Cancer Res 2006;66:8762-8769. 